\title{
LAYERING HABIT OF SUGAR MAPLE ${ }^{1}$
}

\author{
D. C. F. FAYLE ${ }^{2}$
}

\begin{abstract}
$A B S T R A C T$
Natural layering of sugar maple is more common than generally realized. Seedlings, branches, stems and basal sprouts may become layered. Some of these layers could be mistaken for root suckers.

Reproduction of sugar maple (Acer saccharum Marsh.) by root suckers has been reported in the North American literature (Godman, 1957). My investigations in Ontario, however, have failed to uncover reproduction by this means; what appeared to be suckers were stems which had grown from natural layering. Examples are given here to show how some stems could be mistaken for sucker origin, and to demonstrate the propensity of maple to layer from a variety of sources-seedlings, branches, basal sprouts and trees. Most of these layers will produce poor stems as their growth rate is very slow under the conditions conducive to layering, and decay may be present at an early stage. Nevertheless good stems can develop if the layer has an opportunity to grow rapidly and establish its own root system.
\end{abstract}

The investigation showed that one-half to three-quarters of the sugar maple stems in an old growth tolerant hardwood stand had basal sprouts, many of which were layered. The same proportion of seedlings was also layered. Layering of stems or branches flattened in logging or by natural causes was also common. The layered origin, however, is easily missed by a casual inspection as the stems rapidly assume an upright character and the basal portion is obscured by accumulated leaf litter.

Sugar maple seedlings growing in the dense shade of larger trees tend to be weak-stemmed and are easily buried by the accumulation of leaf litter and compacted snow. Flattening may also be aided by an initially procumbent stem, a character of some progenies observed by Gabriel (1962) during inbreeding experiments.

An upright and a layered seedling are shown in Figure 1. The layered seedling (b) may have several years' growth, and therefore buds, buried beneath the litter surface. Roots develop along the buried portion of the stem once it is covered. The later development of such a seedling is shown in (c) and (d). Note that the original root system is gradually replaced by one developing below the new vertical stem. In time (d), the original system is no longer distinguishable, and sprouts appear to originate from a root. The increased number of buds occurring at ground level as a result of such layering, compared with an upright stem, may explain differences in the number of sprouts developing after cutting.

\footnotetext{
${ }^{1}$ Department of Forestry, Canada, Forest Research Branch Contribution No. 540.

${ }^{2}$ Research Officer, Forest Research Branch, Dept. of Forestry, Richmond Hill, Ontario. Biography in For. Chron. $37(1): 10$.
} 

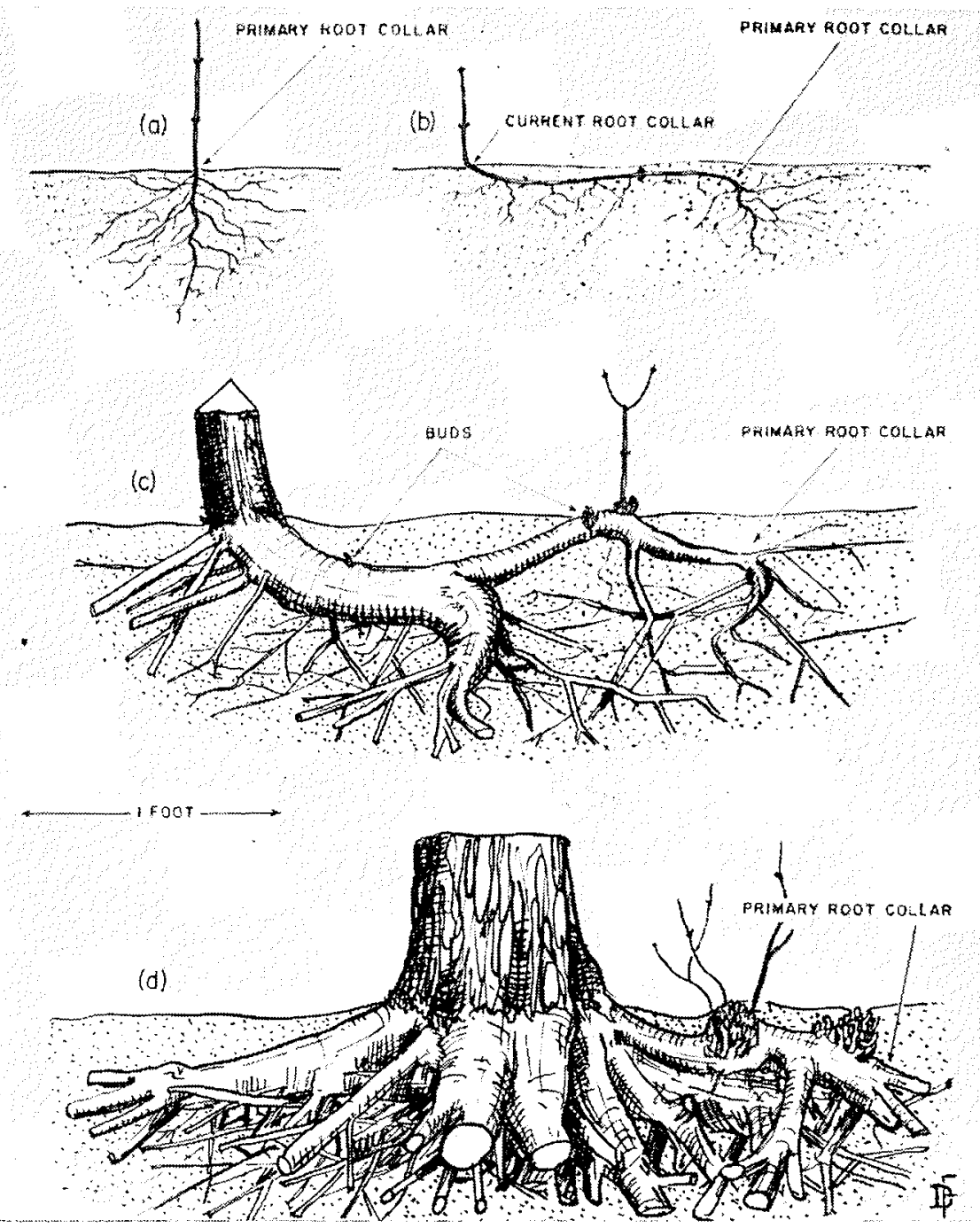

FIGURE 1.(a) Upright and (b) layered seedlings. Development of layered seedling in sapling stage (c) and tree stage (d).

Neither the original root system nor early stem growth is left on the layered stem shown in Figure 2. Adventitious roots occur along the stem and most of the paired buds have remained dormant. 

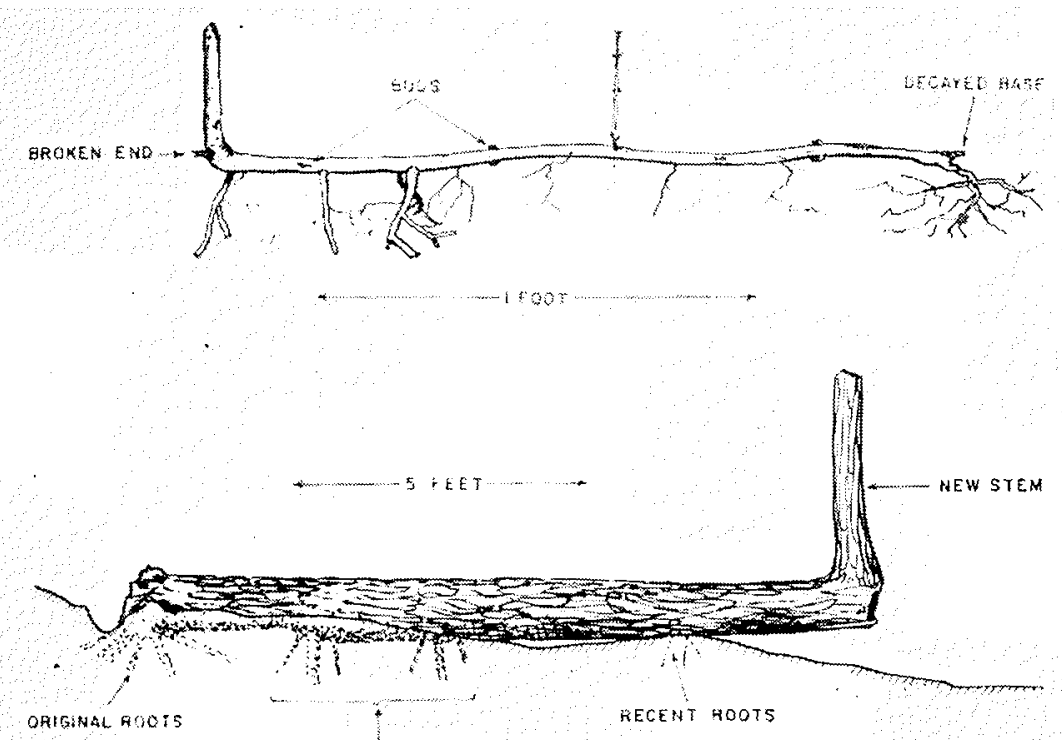

MAIA FOOTING FROM STEM

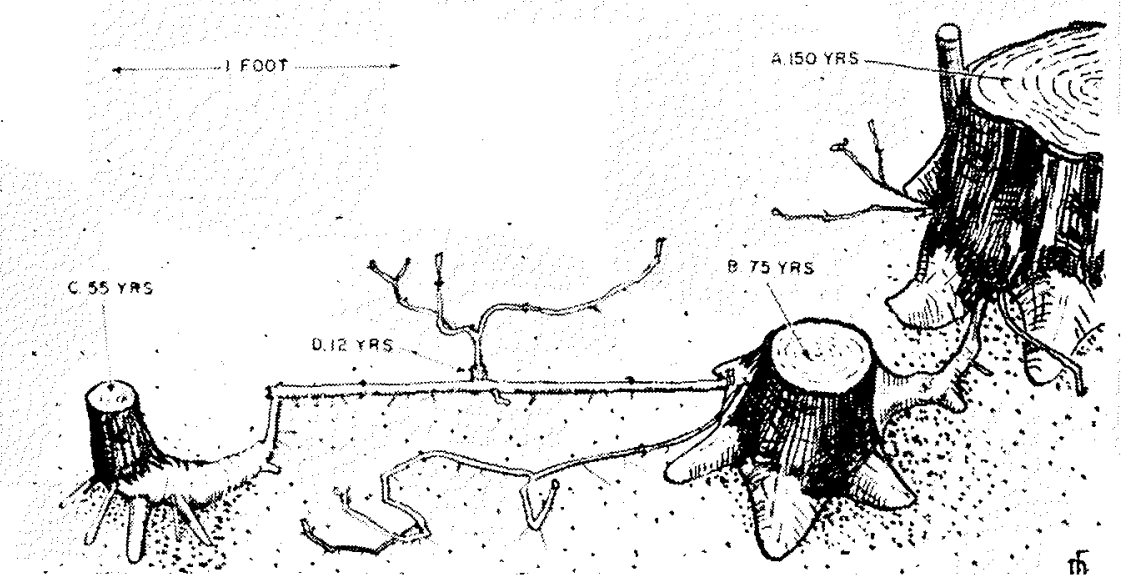

FIGURE 2. (Top). A layered stem in which the original base has decayed.

FIGURE 3. (Middle). Laycring of a tree.

FIGURE 4. (Bottom). Layering from collapsed basal sprouts. The leaf litter has been removed to show connections and rooting. 


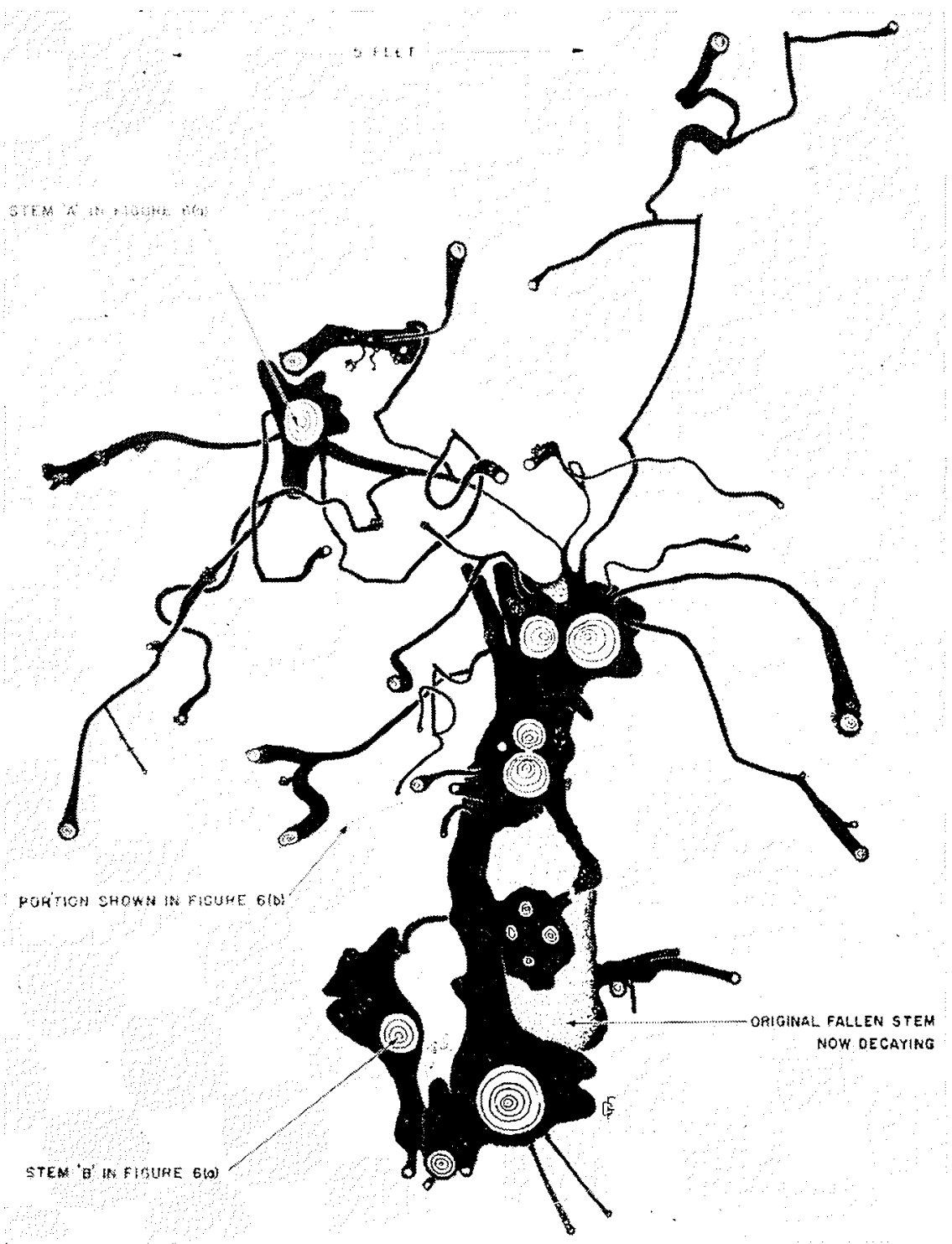

FIGURE 5. A complex family of layers, plan view. Stem material only is shown. 

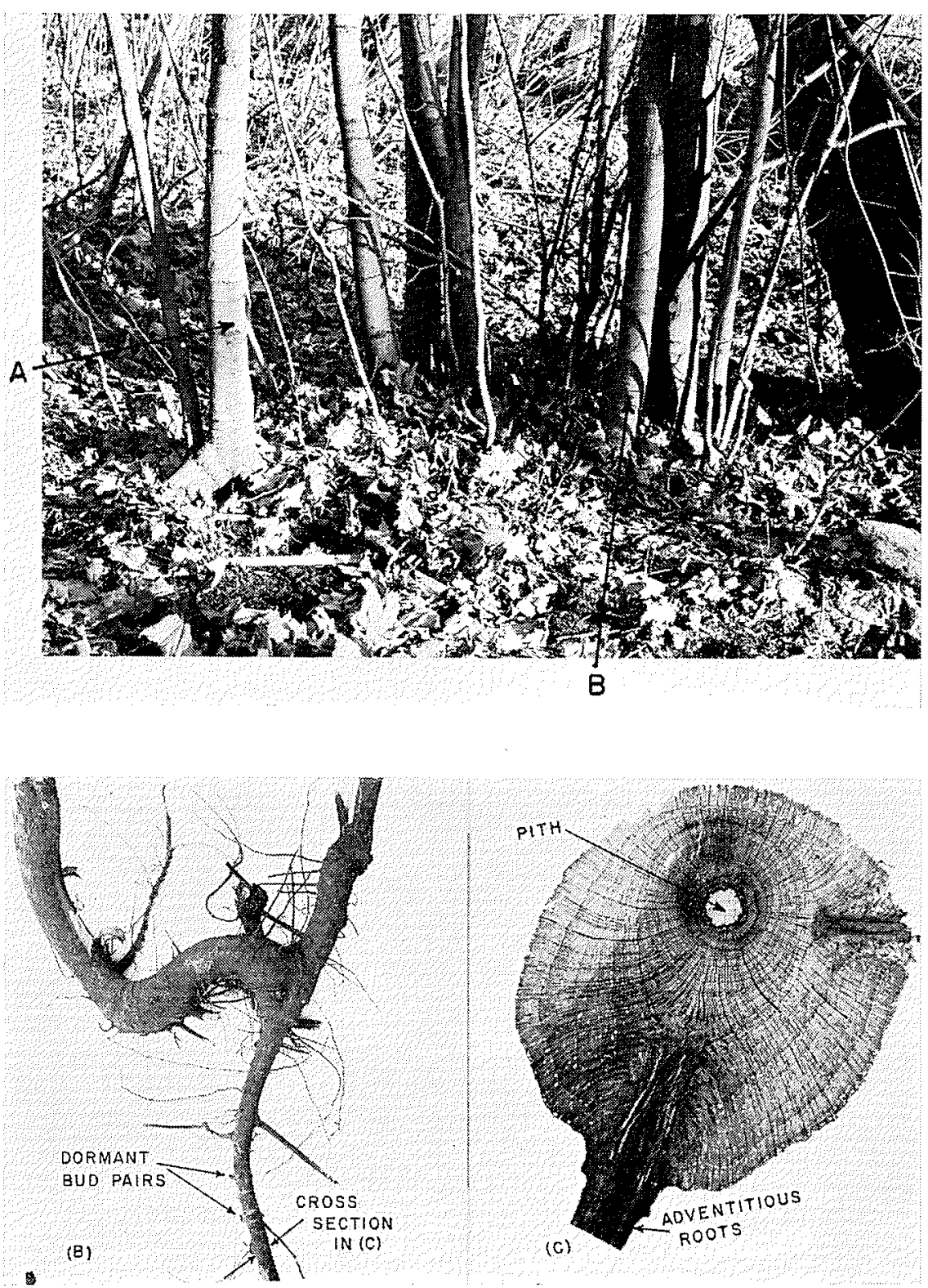

FIGURE 6. (a). (Top). A vicw of the clump shown in Figure 5. (b). (Left) Portion of layer indicated in Figure 5 to show mass of adventitions roors. (c) (Right). Cross section of layered stem shown in (b). 
Particularly striking is the layered stem shown in Figure 3. This tree fell, or was knocked over, about 65 years ago when it was approximately six inches in diameter, 90 years old and perhaps 40 feet tall; the root system was not entirely severed. When found in 1961,12 feet of the original stem lay partly buried in the soil; the top of the tree had broken or decayed during the years; a bud or lateral branch had developed at the end so that an 8-inch tree nearly 50 feet tall was present; and roots had developed from the stem where it was buried in the accumulated leaf litter. As far as could be determined, new roots had started within 15 to 20 years after the fall, but had only developed into an extensive system within the last decade. Some roots emerged recently as more of the stem became buried in the leaf litter. Part of the original root system is still alive, but there is a noticeable increase in stem diameter at the point of adventitious rooting.

Layering of basal sprouts is shown in Figure 4, where a basal sprout from the parent tree $\mathrm{A}$ has collapsed and eventually formed tree $\mathrm{B}$. This in turn developed basal sprouts, and one of these formed tree $C$. Note the persistence of the connections between the stems, the most recent stem $\mathrm{D}$, the collapse of other basal sprouts, the presence of adventitious roots, the well-developed roots on the offspring stems, and the relative ages. Atlhough it is doubtful if much translocation of materials occurs between parent and offspring through the connection once an independent root system is established, root grafting occurs as a result of the proximity of the stems. Thus, even if the original connection decays, the stems remain integrated.

A complex family of layers, originating from a fallen stem, and enlarged by layering of branches and sprouts, is shown in Figures 5 and 6(a). This clump, covering an area of about 150 square feet, was located on a roadside. The mass of adventitious roots, the paired dormant buds, and the obvious pith are revealed in Figures 6(b) and (c). These last two features mark the material as being stem, not root, tissue.

Observations have shown that layering of sugar maple is a common phenomenon, which is attributed mainly to the poor growing conditions existing at ground level in a dense, closed canopy, hardwood stand. Quantitative studies are now required to determine: (1) the importance of layering in the regeneration of hardwood stands, (2) the effect of different growing conditions on the production of layers, (3) whether layering ability varies between individual trees, and (4) the proportion and type of layers that make acceptable trees.

\section{REFERENCES}

GABRIEL, W. J. 1962. Inbreeding experiments in sugar maple (Acer saccbarum Marsh.) -early results. In 9th Northeast. For. Tree Improv. Conf. Proc. (1961) : 8-12.

GODMAN, R. M. 1957. Silvical characteristics of sugar maple. U.S.D.A., For. Serv., Lake States For. Exp. Sta., Sta. Paper 50:24 pp 